\title{
LEVANTAMENTO DOS CASOS DE AVULSÃO DENTÁRIA DO CENTRO ESPECIALIZADO MARINGAENSE DE TRAUMATISMO ODONTOLÓGICO
}

Michelle da Fonseca FREITAS, Ariane Ximenes GRACIANO, Natália Osswald CARLETE, Alfredo Franco QUEIROZ, Nair Narumi Orita PAVAN

A avulsão dentária caracteriza-se pelo completo deslocamento do dente de seu alvéolo, e o melhor prognóstico está diretamente relacionado ao tempo extra-alveolar antes do reimplante e com as condições sob as quais o dente foi armazenado. As lesões traumáticas dentárias se caracterizam como um dos mais sérios problemas de saúde bucal entre crianças e adolescentes e representam uma das causas mais comuns de procura dos serviços de pronto-atendimento. $\mathrm{O}$ objetivo deste trabalho foi analisar através de prontuários odontológicos os casos de avulsões dentárias que compareceram ao Centro Especializado Maringaense de Traumatismo Odontológico (CEMTrau-Odonto) da Universidade Estadual de Maringá. A pesquisa foi realizada através da análise de 50 prontuários odontológicos dos casos de avulsões dentárias do Projeto CEMTrau-Odonto. Os pacientes possuíam idade entre 2 e 44 anos sendo que $34 \%$ se concentravam entre 2 e 9 anos e 19\% dos casos foram causados por quedas de bicicleta. O reimplante foi realizado em $56 \%$ dos casos e $37 \%$ dos dentes foram mantidos a seco por mais de 30 minutos. Sabendo disso, os profissionais devem estar preparados para receber pacientes com história de traumatismos, sejam eles simples como uma fratura de esmalte, ou até mais complexos, como a avulsão. 